\title{
Analisa Teoritis Laju Aliran Kalor Pada Ketel Uap Pipa Api Mini Industri Tahu Di Tinjau Dari Koefisien Perpindahan Panas Menyeluruh
}

\author{
Legisnal Hakim \\ Program Studi Teknik Mesin, Fakultas Teknik \\ Universitas Muhammadiyah Riau \\ e-mail: legisnalhakim @umri.ac.id
}

\begin{abstract}
Abstrak
Ketel uap pada industry Tahu merupakan alat pendukung dalam proses pengolahan tahu, yang secara tidak langsung menjadi bagian yang terpenting untuk meningkatkan produktivitas pengolahan Tahu di dunia industry kecil, menengah dan besar pada pabrik Tahu. Pada rancangan ketel uap pipa api mini dari PDP 1 (2014) bahwa laju aliran kalor pada pipa api belum dilakukan analisa teoritis, untuk itu perlu dilakukan penghitungan laju aliran kalor berdasarkan panjang pipa, diameter pipa atau tebal pipa, serta konduktivitas thermal pada bahan pipa dan juga koefisien perpindahan panas, dari ketel uap pipa api mini ini bahwa terjadi perpindahan panas secara radiasi, konduksi dan konveksi. Dari PDP 1 sudah dihasilkan spesifikasi ketel dan modelnya, yaitu ketel uap pipa api dan berbentuk horizontal, yang memiliki spesifikasi diameter drum $1000 \mathrm{~mm}$, panjang drum $1200 \mathrm{~mm}$, tebal plat drum $5 \mathrm{~mm}$, diameter pipa api $125 \mathrm{~mm}$, tebal 2,5 mm, tebal tubesheet $5 \mathrm{~mm}$, jarak antara pipa api 203,2 mm, diameter pipa nosel 25,4 dan 50,8 mm, tebal pipa nosel 1,1 $\mathrm{mm}$ dan 1,24 mm. untuk sumber kalor yang di gunakan adalah sumber kalor yang dihasilkan oleh dapur dari hasil rancangan PDP 2 ( 2016 dengan temperature dalam dapur diambil $980^{\circ} \mathrm{C}$, laju perpindahan panas dalam dapur adalah $44 \mathrm{~kW}$.
\end{abstract}

Kata kunci : Ketel uap, pipa api

\section{Pendahuluan}

Ketel uap pipa api ini merupakan ketel uap yang diaplikasikan pada lokomotif dan menghasilkan tekanan paling besar $10 \mathrm{~kg} / \mathrm{cm}^{2}$, ketel uap ini modelnya adalah horizontal berarti panas yang mengalir didalam pipa api secara linier atau lurus horizontal, ketel juga merupakan alat penukar kalor, sehinggan prinsip - prinsip alat penukar kalor juga bisa diaplikasikan disini tentu laju aliran panas pada pipa horizontal pada saat panas mengalir dan mentransfernya kepermukaan pipa api bagian dalam yang terkena panas mempengaruhi waktu perebusan air didalam drum dan juga apakah pemilihan pipa dan ukuran diameter pipa sesuai dengan pemakaian atau perancangan. Dengan diameter pipa api yang direncanakan $125 \mathrm{~mm}$, tebal 2,5 $\mathrm{mm}$ dan temperature awal air $30{ }^{\circ} \mathrm{C}$, temperature uap max. $150{ }^{0} \mathrm{C}$, temperature dapur $980{ }^{\circ} \mathrm{C}$ dengan kapasitas panas $44 \mathrm{~kW}$ yang disebut juga sebagai sumber energi, Apakah pemilihan pipa yang belum ditentukan atau penggunaan pipa dapat menghasilkan laju perpindahan panas pada pipa api dapat diaplikasikan, maka untuk perlu dilakukan analisa toeritis perpindahan panas untuk pemilihan pipa. Dengan tujuan mengetahui laju perpindahan panas pada ketel uap pipa api model horizontal.

Prinsip - prinsip perpindahan panas pada ketel uap merupakan prinsip utama dalam perancangan dan pengembangan ketel uap dan juga ketel uap merupakan sebagai alat penukar kalor, karena ketel uap berfungsi mengubah fase media cair menjadi fase cair jenuh, fase uap jenuh dan fase uap super jenuh. Dari perubahan fase ini perlu energy untuk merubah enthalpy zat cair untuk menghasilkan temperature dan tekanan dengan meningkatkan entalpi melalui proses/siklus tekanan vs volime spesifik dan temperature vs entropi semua bisa dihasilkan melalui proses perpindahan panas. Ada beberapa prinsip perpindahan panas secara umum yaitu :
a. Konduksi
b. Konveksi
c. Radiasi

\subsection{Konduksi.}

Konduksi adalah perpindahan kalor melalui zat perantara tanpa disertai perpindahan partikelpartikel zat, umumnya melalui zat padat. Faktor- 
faktor yang mempengaruhi laju konduksi kalor :

1. Beda suhu antara kedua permukaan $(\Delta \mathbf{T})$ makin besar beda suhu, makin cepat perpindahan kalor.

2. Jarak antara kedua permukaan /tebal /panjang (l), makin tebal, makin lambat perpindahan kalor.

3. Luas permukaan (A), makin luas permukaan makin cepat perpindahan kalor.

4. Konduktivitas termal zat (k), merupakan ukuran kemampuan zat menghantarkan kalor; makin besar nilai $\mathrm{k}$, makin cepat perpindahan kalor.

Perpindahan panas konduksi steady state (tunak), koordinat satu dimensi meliputi antara lain :

- $\quad$ Bidang datar, koordinat kartesian $(\mathrm{x}, \mathrm{y}, \mathrm{z})$

- Selinder, koordinat selinder $(r, z, \theta)$

- Bola, koordinat bola (r, $\theta, \phi)$

Laju Konduksi Kalor dapat dtuliskan dengan persamaan menurut hukum Fourier :

Dimana :

$$
\begin{gathered}
Q_{k}=k A\left(-\frac{d T}{d x}\right) \\
\frac{Q_{k}}{A}=k\left(-\frac{d T}{d x}\right)
\end{gathered}
$$

$\mathrm{Q}=$ Laju perpindahan panas per waktu $(\mathrm{W})$

$\mathrm{k}=$ Konduktivitas thermal material $\left(\mathrm{W} / \mathrm{m} .{ }^{0} \mathrm{C}\right)$

$\mathrm{A}=$ Luas permukaan bidang terkena panas $\left(\mathrm{m}^{2}\right)$

$\mathrm{dT} / \mathrm{dx}=$ Gradien suhu

Konduktivitas Thermal (Daya Hantar Panas) Adalah sifat bahan yang menunjukkan seberapa cepat bahan itu dapat menghantarkan panas konduksi Pada umumnya nilai $\mathrm{k}$ dianggap tetap, namun sebenarnya nilai $\mathrm{k}$ dipengaruhi oleh suhu $(\mathrm{T})$. Konduktor $\rightarrow$ bahan yang mempunyai konduktivitas yang baik Contoh : logam Isolator $\rightarrow$ bahan yang mempunyai konduktivitas yang jelek Contoh : asbes

Perpindahan Panas Konduksi pada Silinder Berongga. Suatu silinder panjang berongga dengan jari-jari dalam $r_{i}$, jari-jari luar $r_{o}$ dan panjang L dialiri panas sebesar Q. Suhu permukaan dalam $\mathrm{T}_{\mathrm{i}}$ dan suhu permukaan luar $\mathrm{T}_{\mathrm{o}}$.

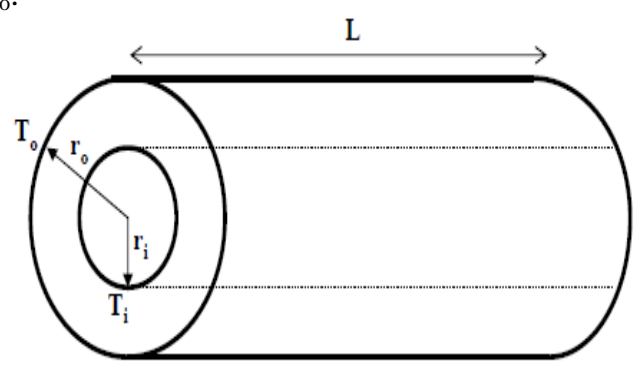

Analogi listrik :

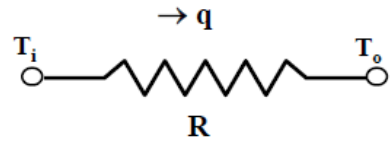

Gambar 1. Selinder dan analogi listrik

Aliran panas hanya berlangsung ke arah radial (arah r) saja. Luas bidang aliran panas dalam system silinder ini adalah :

$\mathrm{Ar}=2 \pi \mathrm{rL}$

Sehingga hukum Fourier menjadi:

$$
Q=k A\left(-\frac{d T}{d r}\right)=-k 2 \pi r L\left(\frac{d T}{d r}\right)
$$

Kondisi batas ( Boundary condition, BC)

(i)

(ii)

$$
\begin{aligned}
& \mathrm{r}=\mathrm{r}_{\mathrm{i}} \longrightarrow \mathrm{T}=\mathrm{T}_{\mathrm{i}} \\
& \mathrm{r}=\mathrm{r}_{\mathrm{o}} \longrightarrow \mathrm{T}=\mathrm{T}_{\mathrm{o}}
\end{aligned}
$$

Dengan kondisi batas di atas, persamaan aliran panas untuk koordinat silinder adalah :

$$
\begin{aligned}
& Q=\frac{2 \pi k L\left(T_{i}-T_{o}\right)}{\ln \left(\frac{r_{o}}{r_{i}}\right)} \\
& Q=\frac{\Delta T}{R_{t h}} \\
& \mathrm{R}_{\mathrm{th}}=\text { Tahanan termal }=\frac{\ln \left(\frac{r_{o}}{r_{i}}\right)}{2 \pi k L} \\
& Q=\frac{\Delta T}{\frac{\ln \left(r_{o} / r_{i}\right)}{2 \pi k L}}
\end{aligned}
$$

Jika D adalah diameter silinder maka :

$$
\frac{r_{o}}{r_{i}}=\frac{D_{o}}{D_{i}}
$$

Persamaan aliran panas dapat ditulis,

$$
Q=\frac{2 \pi k L\left(T_{i}-T_{O}\right)}{\ln \frac{D_{O}}{D_{i}}}
$$

Jika diameter dalam silinder (Di) > 0,75 diameter luar (Do), aliran panas bisa dicari dengan :

$$
Q=\frac{T_{i}-T_{o}}{\frac{\left(D_{o}-D_{i}\right) / 2}{\pi k L\left(D_{i}+D_{o}\right) / 2}}
$$

\subsection{Konveksi.}

Konveksi (aliran) adalah perpindahan kalor melalui zat perantara, diikuti perpindahan partikel-partikel zat. Umumnya melalui fluida, misal : udara, air

Macam konveksi :

1. Konveksi alami, contoh : angin darat, angin laut, aliran udara melalui ventilasi / cerobong asap. 
2. Konveksi paksa, contoh : konveksi udara pada hair dryer, sistem pendingin mesin mobil lemari es, AC.

Manfaat konveksi kalor: Proses pemanasan air dalam suatu panci. Partikel air pada dasar panci menerima kalor dan menjadi panas. Pertikel yang telah panas bergerak ke atas karena berat jenisnya mengecil, Sedangkan air dingin turun menempati tempat yang ditinggalkan air panas yang naik.Demikian ini terjadi selama air dipanaskan, sehingga air masak secara merata.

\section{Faktor-faktor yang mempengaruhi laju kalor} konveksi :

$>\quad$ Luas permukaan benda (A), semakin luas permukaan benda yang bersentuhan dengan fluida, semakin cepat kalor dipindahkan.

$>$ Perbedaan suhu $(\Delta \mathrm{T})$, semakin besar beda suhu benda dengan permukaan fluida, semakin cepat kalor dipindahkan

$>$ Koefisien konveksi (h), bergantung pada bentuk, kedudukan permukaan dan diperoleh dengan percobaan. Misal h tubuh manusia adalah $7,1 \mathrm{Js}^{-1} \mathrm{~m}^{-2} \mathrm{~K}^{-1}$

\section{Laju kalor konveksi dapat dituliskan dalam} persamaan :

$$
\frac{Q}{t}=h \cdot A \cdot \Delta T
$$

Dimana :

$\mathrm{Q} / \mathrm{t}=$ Laju perpindahan panas konveksi (J/s)

$\mathrm{h}=$ Koefisiesn perpindahan panas konveksi $\left(\mathrm{W} / \mathrm{m}^{2} .{ }^{0} \mathrm{C}\right)$

$\mathrm{A}=$ Luas permukaan kena panas $\left(\mathrm{m}^{2}\right)$

$\Delta \mathrm{T}=$ Perbedaan suhu ( temperature dinding $\mathrm{T}_{\mathrm{w}}-$ temperature fluida $\left.\mathrm{T}_{\infty}\right),{ }^{0} \mathrm{C}$

\section{Koefisien Perpindahan Panas Menyeluruh (Overall Heat Transfer Coefficient, U)}

Adalah merupakan aliran panas menyeluruh sebagai hasil gabungan proses konduksi dan konveksi. Koefisien perpindahan panas menyeluruh dinyatakan dengan $\mathrm{W} / \mathrm{m}^{2} .{ }^{\circ} \mathrm{C}$ (Btu/h.ft $\left.{ }^{2}{ }^{\circ} \mathrm{F}\right)$

\section{Koefisien Perpindahan Panas Menyeluruh Pada Silinder}

Suatu silinder berongga terkena lingkungan konveksi dipermukaan bagian dalam dan luar oleh fluida A dan fluida B. Suhu kedua fluida, $\mathrm{T}_{\mathrm{A}}$ $\operatorname{danT}_{B}$. Zat alir mengalir melalui pipa pada suhu $\mathrm{T}_{\mathrm{A}}$. Perpindahan panas dari zat alir ke pipa secara konveksi diteruskan lewat pipa secara konduksi dan selanjutnya ke zat alir yang ada di luar pipa pada suhu $\mathrm{T}_{\mathrm{B}}$ secara konveksi.

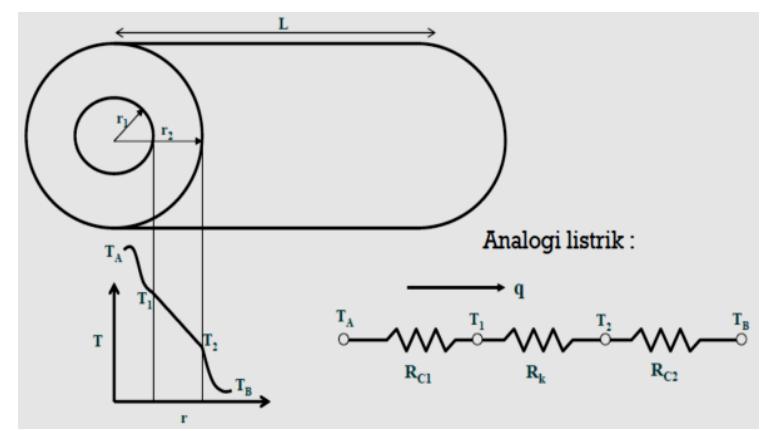

Gambar 2. selinder dengan lingkungan konveksi.

Perpindahan panas menyeluruh dari zat alir didalam pipa ke zat alir diluar pipa adalah

$$
Q=\frac{T_{A}-T_{B}}{\frac{1}{h_{1} \cdot A_{1}}+\frac{\ln \left(r_{2} / r_{1}\right)}{2 \pi k L}+\frac{1}{h_{2} \cdot A_{2}}}
$$

Luas permukaan untuk perpindahan panas zat alir :

- Di dalam pipa, $\mathrm{A}_{\mathrm{i}}=2 \pi \mathrm{r} \mathrm{L}$

- Di luar pipa, $A_{0}=2 \pi r \mathrm{~L}$.

Sehingga,

$$
\begin{aligned}
& Q=\frac{T_{A}-T_{B}}{\frac{1}{h_{1} \cdot 2 \pi r_{1} L}+\frac{\ln \left(r_{2} / r_{1}\right)}{2 \pi k L}+\frac{1}{h_{2} \cdot 2 \pi r_{2} L}} \\
& \frac{2 \pi L\left(T_{A}-T_{B}\right)}{\frac{1}{h_{1} \cdot r_{1}}+\frac{\ln \left(r_{2} / r_{1}\right)}{k}+\frac{1}{h_{2} \cdot r_{2}}}
\end{aligned}
$$

Koefisien perpindahan panas menyeluruh dapat didasarkan atas bidang dalam atau bidang luar tabung.

\section{- Bidang dalam,}

$$
\begin{array}{r}
Q=\frac{A_{1}\left(T_{A}-T_{B}\right)}{\frac{1}{h_{1} \cdot}+\frac{\mathrm{A}_{1} \ln \left(r_{2} / r_{1}\right)}{2 \pi k L}+\frac{A_{1}}{h_{2} \cdot A_{2}}} \\
=\frac{2 \pi r_{1} L\left(T_{A}-T_{B}\right)}{\frac{1}{h_{1}}+\frac{r_{1} \ln \left(r_{2} / r_{1}\right)}{k}+\frac{r_{1}}{h_{2} \cdot r_{2}}}
\end{array}
$$

$U_{1}=\frac{1}{\frac{1}{h_{1}}+\frac{r_{1} \ln \left(\frac{r_{2}}{r_{1}}\right)}{k}+\frac{r_{1}}{h_{2} \cdot r_{2}}}$

- Bidang luar,

$$
\begin{gathered}
Q=\frac{A_{2}\left(T_{A}-T_{B}\right)}{\frac{A_{2}}{h_{1} \cdot A_{1}}+\frac{\mathrm{A}_{2} \ln \left(r_{2} / r_{1}\right)}{2 \pi k L}+\frac{1}{h_{2} .}} \\
=\frac{2 \pi r_{2} L\left(T_{A}-T_{B}\right)}{\frac{r_{2}}{h_{1} r_{1}}+\frac{r_{2} \ln \left(r_{2} / r_{1}\right)}{k}+\frac{1}{h_{2} .}} \\
U_{2}=\frac{1}{\frac{r_{2}}{h_{1} r_{1}}+\frac{r_{2} \ln \left(\frac{r_{2}}{r_{1}}\right)}{k}+\frac{1}{h_{2}}}
\end{gathered}
$$




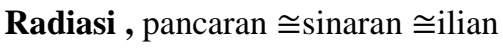

Radiasi thermal $\rightarrow$ radiasi elektromagnetik yang dipancarkan oleh suatu benda karena suhunya.

Radiasi selalu merambat dengan kecepatan cahaya, $3 \times 10^{10} \mathrm{~cm} / \mathrm{s}$. Kecepatan ini sama dengan hasil perkalian panjang gelombang dengan frekuensi radiasi : $\mathrm{C}=\lambda . \mathrm{V}$

dimana:

$$
\begin{aligned}
& \mathrm{c}=\text { kecepatancahaya } \\
& \lambda=\text { panjanggelombang }\left(=10^{-8} \mathrm{~cm}\right) \\
& \nu=\text { frekuensi }
\end{aligned}
$$

Perambatan radiasi thermal berlangsung dalam bentuk kuantum dan setiap kuantum mengandung energy sebesar : $\mathrm{E}=\mathrm{h} . \mathrm{v}$

$\mathrm{h}=$ konstanta Planck, 6,625 x $10^{-34} \mathrm{~J} . \mathrm{s}$

Setiap kuantum dianggap sebagai suatu partikel yang mempunyai energi, massa dan momentum seperti molekul gas $\rightarrow$ photon. Sehingga, pada hakekatnya radiasi merupakan pancaran yang disebabkan oleh gas photon yang mengalir dari satu tempat ke tempat lain. Dengan teori relatifitas dan thermodinamika statistic maka akan diperoleh suatu rumus yang disebut Hukum Stefan-Boltzmann dimana energy total yang dipancarkan oleh suatu benda sebanding dengan pangkat empat suhu absolut: $\mathrm{E}_{\mathrm{b}}=\varepsilon . \sigma . \mathrm{A} . \mathrm{T}^{4}$

Dilihat dari daya

emisinya, benda terbagi

ke dalam 3 macam :

1.Benda putih sempurna (absolutely white) $\rightarrow$ menyerap sinar, tanpa mengemisikan kembali.

Emisivitas $(\varepsilon)=0$

2.Benda abu-abu (gray body) $0<\varepsilon<1$

3.Benda hitam (blackbody) $\rightarrow$ menyerap $100 \%$, mengemisikan $100 \%$. Emisivitas $(\varepsilon)=1$

\section{Metodologi}

Perlu dilakukan langkah - langkah analisa teoritis laju perpindahan panas dengan model koefisien perpindahan panas menyeluruh pada ketel uap pipa api mini model horizontal. Untuk itu perlu disiapkan instrument untuk analisa tersebut, adapun instrument tersebut adalah pengumpulan data sekunder atau primer, analisa kuantitatif atau kualitatif. Untuk metode penelitian ini menggunakan data sekunder yang didapat dari literature dan hasil penelitian sebelumnya (PDP 1, legisnal Hakim - 2014 dan PDP 2, legisnal Hakim - 2016) dan analisa kuantitatif (dengan persamaan perpindahan panas).

\section{Analisa dan Pembahasan}

Pengumpulan data sekunder dari Penelitian dosen pemula (PDP) yaitu :
Ketel uap pipa api mini dari PDP 1, (Legisnal Hakim, 2014) :

Diameter drum ketel $\left(\mathrm{D}_{\text {drum }}\right) \quad=100 \mathrm{~cm}$

Panjang drum $\left(\mathrm{P}_{\text {drum }}\right) \quad=120 \mathrm{~cm}$

Tebal drum $\left(\mathrm{t}_{\text {drum }}\right) \quad=0.06 \mathrm{~cm}$

Diameter dalam pipa api $\left(\mathrm{D}_{\mathrm{i}, \text { pipa api }}\right)=12,5 \mathrm{~cm}$ $(0,125 \mathrm{~m})$

Tebal pipa api $\left(\mathrm{t}_{\text {pipa api }}\right) \quad=0,025 \mathrm{~cm} \approx 0,03$

Diameter luar pipa api $\left(\mathrm{D}_{\mathrm{o}}\right.$, pipa api $)=13,1 \mathrm{~cm}$ (0,131 m)

Panjang pipa api $\left(\mathrm{P}_{\text {pipa api }}\right) \quad=120 \mathrm{~cm}$

Jarak antara pipa api $\quad=20,32 \mathrm{~cm}$

Kapasitas panas (Q) $\quad=44 \mathrm{~kW}$

Temperatur awal air $\quad=30{ }^{\circ} \mathrm{C}$

Dapur ketel uap pipa api mini dari PDP 2, (legisnal Hakim, 2016) :

Panjang dapur $\left(\mathrm{P}_{\text {dapur }}\right) \quad=100 \mathrm{~cm}$

Lebar dapur $\left(\mathrm{L}_{\text {dapur }}\right) \quad=43,5 \mathrm{~cm}$

Tinggi dapur $\left(\mathrm{T}_{\text {dapur }}\right) \quad=78 \mathrm{~cm}$

Tebal dinding dapur $\left(\mathrm{t}_{\text {dapur }}\right) \quad=7 \mathrm{~cm}$

Diameter lubang garangan $\quad=3,5 \mathrm{~cm}$

Jumlah lubang garangan = 97 lubang

Pengumpulan data sekunder dari literature yaitu :

Temperature dapur $=(540-980){ }^{0} \mathrm{C} ; 600{ }^{0} \mathrm{C}$ diambil (tungku suhu rendah Tabel 2, UNEP 2006 ).

\begin{tabular}{|c|c|c|c|c|c|}
\hline $\begin{array}{l}\mathrm{T}, \\
{ }^{0} \mathrm{C}\end{array}$ & $\begin{array}{l}\mathrm{k},(\mathrm{W} / \mathrm{m} . \\
\left.{ }^{0} \mathrm{C}\right)\end{array}$ & $\begin{array}{l}\mathrm{T}, \\
{ }^{0} \mathrm{C}\end{array}$ & $\begin{array}{l}\mathrm{k}, \\
\left(\mathrm{W} / \mathrm{m} .{ }^{0} \mathrm{C}\right)\end{array}$ & $\begin{array}{l}\mathrm{T}, \\
{ }^{0} \mathrm{C}\end{array}$ & $\begin{array}{l}\mathrm{k}, \\
\left(\mathrm{W} / \mathrm{m} .{ }^{0} \mathrm{C}\right)\end{array}$ \\
\hline 0 & 0.55187 & 60 & 0.65048 & 120 & 0.68508 \\
\hline 20 & 0.59685 & 80 & 0.66778 & 140 & 0.68335 \\
\hline 40 & 0.62799 & 100 & 0.67989 & 160 & 0.67989 \\
\hline
\end{tabular}

Konduktivitas air (perpindahan kalor tabel B3, Donald R. Pitts)

Konduktivitas termal air $30^{\circ} \mathrm{C}=0,61244 \mathrm{~W} / \mathrm{m} .{ }^{0} \mathrm{C}$ Koefisien perpindahan panas konveksi air $=$ $\mathrm{h}_{\mathrm{o}}=9,35 \mathrm{w} / \mathrm{m}^{20} \mathrm{C}$

$\mathrm{r}_{\mathrm{i}}=\mathrm{D}_{\mathrm{i}} / 2=0.0625 \mathrm{~m}$

$\mathrm{r}_{\mathrm{o}}=\mathrm{D}_{\mathrm{o}} / 2=0.0655 \mathrm{~m}$

$$
\begin{gathered}
r_{o}=\frac{k_{\text {air }}}{h_{\text {air }}} \\
h=\frac{k_{\text {air }}}{r_{0}}=\frac{0,61244}{0,0655}=9,35 \frac{W}{\mathrm{~m}^{2} \cdot C}
\end{gathered}
$$

Koefisien perpindahan panas konveksi gas pembakaran, $h_{i}$

$$
\begin{aligned}
h_{i}=\frac{Q}{A\left(T_{\infty}-T_{w}\right)} & =\frac{\mathrm{hA}\left(\mathrm{T}_{\infty}-\mathrm{T}_{\mathrm{w}}\right)}{\pi \times 0,125^{2} \times(600-30)} \\
& =\frac{176000}{28}=6286 \mathrm{~W} / \mathrm{m}^{2} \mathrm{C}
\end{aligned}
$$

Pipa api yang digunakan untuk ketel ini adalah seamless carbon steel SA 53 Grade B untuk ketel uap pada ASME Section IV. Dimana konduktivitas thermal untuk baja karbon adalah 
Tabel A-2 Sifat - sifat metal ( JP Holman), baja karbon $0,5 \% \mathrm{C}$, Temperatur $800{ }^{0} \mathrm{C}, \mathrm{k}=31$ $\mathrm{W} / \mathrm{m} .{ }^{0} \mathrm{C}$.

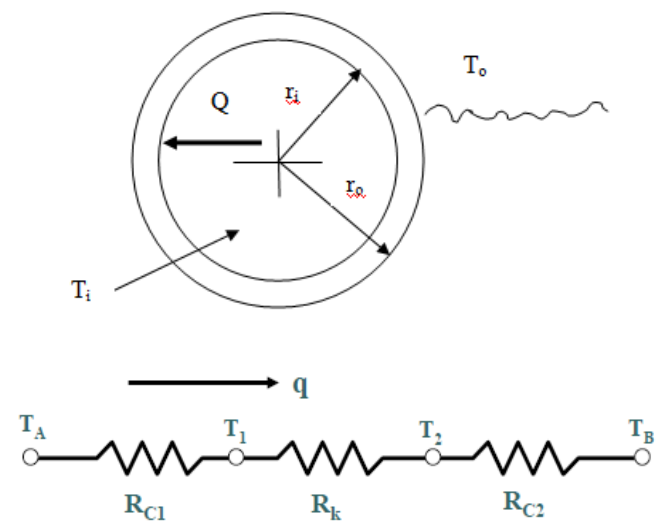

Gambar 3. Perpindahan panas pada pipa api dan Analogi listrik

Laju perpindahan panas pada pipa api dari koefisien perpindahan panas menyeluruh adalah :

$$
\begin{gathered}
Q=\frac{\Delta T}{\sum R}=U A \Delta T \\
R_{i}=\frac{1}{h_{i} A_{i}}=\frac{1}{6286 \times \pi \times 0,125 \times 1.2}=\frac{1}{2961} \\
=0.000338 \mathrm{C} / \mathrm{W} \\
R_{t}=\frac{\ln \left(d_{o} / d_{i}\right)}{2 \pi k L}=\frac{\ln (0,131 / 0.125)}{2 \times 3.14 \times 31 \times 1.2} \\
=\frac{0.04688}{233,6}=0,0002 \mathrm{C} / \mathrm{W} \\
R_{o}=\frac{1}{h_{o} \cdot A_{o}}=\frac{1}{9.35 \times 2 \times \pi \times 0.131 \times 1.2} \\
=\frac{1}{9.23}=0.108 \mathrm{C} / \mathrm{W} \\
U_{o}=\frac{1}{A_{o} \sum R}=18,66 \mathrm{~W} / \mathrm{m}^{2} \mathrm{C} \\
=\frac{1}{\pi \times 0.131 \times 1,2) \times(0,000338+0.0002+0,108)}
\end{gathered}
$$

$$
\begin{aligned}
& U_{i}=\frac{1}{A_{i} \sum R} \\
& =\frac{1}{\pi \times 0.125 \times 1.2 \times(0,000338+0.0002+0,108)} \\
& U_{i}=\frac{1}{0,0511}=19.57 \mathrm{~W} / \mathrm{m}^{2} \mathrm{C} \\
& \mathrm{Q}=\mathrm{U}_{\mathrm{i}} \mathrm{A}_{\mathrm{i}} \Delta \mathrm{T}=19,57 \times 0,5 \times(600-30)=5577,5 \\
& \mathrm{~W}
\end{aligned}
$$

Laju perpindahan panas konduksi untuk panjang pipa L :

$$
\begin{gathered}
Q=-2 \pi L k \frac{T_{O}-T_{i}}{\ln \frac{r_{O}}{r_{i}}+\frac{k}{h r_{i}}} \\
=-2 \times \pi \times 1.2 \times 31 \frac{30-600}{\ln \frac{0,0655}{0,0625}+\frac{31}{6286 \times 0,0625}} \\
=\frac{133161}{0,127}=\mathbf{1 0 4 8 5 1 2} \mathbf{W}
\end{gathered}
$$

Dari hasil perhitungan diatas berdasarkan koefisien perpindahan panas menyeluruh laju perpindahan panas pada bagian dalam pipa adalah $5577,5 \mathrm{~W}$ dan bagian luar pipa $5318 \mathrm{~W}$, dan laju perpindahan panas konduksi dengan panjang pipa 1,2 $\mathrm{m}$ adalah $1048512 \mathrm{~W}$, dari hasil laju perpindahan panas dapat diperkirakan besar efisiensi yang terjadi pada pipa api ketel uap untuk satu lubang yaitu :

$$
\begin{gathered}
\eta_{p a}=\frac{Q_{O}}{Q_{i}} \times 100 \% \\
\eta_{p a}=\frac{5318}{5577,5}=0,95=95 \%
\end{gathered}
$$

\section{Kesimpulan}

Dengan menggunakan koefisien perpindahan panas menyeluruh ( konveksi dan konduksi ) dapat dibuat simpulan sementara dengan ketebalan pipa, pemilihan pipa dan material pipa dapat mentransfer panas dengan selisih laju kalor panas yang terjadi dalam pipa api dan air adalah 5577,5 $5318=259,5 \mathrm{~W}$ dengan efisiensi laju perpindahan panasnya 95\%. Laju peprpindahan panas konduksi dengan panjang pipa $1,2 \mathrm{~m}$ adalah $1048512 \mathrm{~W}$ Jadi kemampuan material pipa sangat baik untuk mentransfer panas ke air. Tapi untuk mendapatkan hasil yang komplek dan 
menghasilkan rancangan ketel uap pipa api mini yang baik perlu dilakukan pengkajian yang lebih dalam tentang pengaruh radiasi dari gas panas pembakaran dari tungku ke pipa api.

\section{Daftar Pustaka}

Donald R. Pitts, 1997, "heat transfer", (Schaum's outline series), McGraw-Hill

Frank Kreith, Raj. M. Manglik, Mark S. 2011," Principles of Heat Transfer", $7^{\text {th }}$ ed. Cengage Learning

Holman J.P , 2009," Heat Transfer," $10^{\text {th }}$ ed. Mcgraw-Hill series in mechanical engineering)

Legisnal Hakim, Purwo Subekti, 2014," Rancang Bangun Ketel Uap mini dengan Pendekatan Standar SNI Berbahanbakar Cangkang Sawit untuk Kebutuhan Pabrik Tahu Kapasitas 200 kg kedelai/hari", .Jurnal APTEK, Vol 7 ISSN 20852630.

Legisnal Hakim, Sunaryo, 2016," Rancang Bangun Dapur Ketel Uap Pipa Api Mini Model Horizontal Alat Pendukung Industri Tahu Dengan Jenis Bahanbakar Biomassa", laporan PDP 2, kemenristekdikti

Myer Kutz, "2006, “ Heat Transfer Calculation", Copyright (C) 2006 by The McGraw-Hill Companies.

Yunus A. Cengel,2002, "Heat Transfer A Practical Approach", $2^{\text {th }}$ ed. 